\title{
Assessment of Website Quality based on Appearance
}

\author{
B. Vishnu Priya ${ }^{1}$, Dr. JKR Sastry ${ }^{2}$ \\ ${ }^{1}$ Koneru Lakshmaiah Education Foundation, Vaddeswaram, India, vishnupriya574@ gmail.com \\ ${ }^{2}$ Koneru Lakshmaiah Education Foundation, Vaddeswaram, India, drsastry@ kluniversity.in
}

\begin{abstract}
Information is being presented these days in terms of text, data, images, video, and audio, graphics, and animations on websites. Information disseminated through web sites that are either dynamic or static. Quality of the WEB site is, however, a big question. Users are quite concerned about the quality of the WEB site. Too many operations, if needed, are undertaken for want of quality visualization of the content such as images, then the users lose interest in looking at that kind of content. WEB sites are presenting the content by integrating text and data with multimedia objects. Quality visualization in terms of the look and feel of the websites would be the real issue. The number of operations that the user is expected to carry should be minimum.
\end{abstract}

Quality presentation of look and feel is most important for making available web sites to customer satisfaction. Assessment of quality of look and feel is needed to project the extent to which the users will be satisfied with a web site that hosts different types of objects.

In this paper, a comprehensive method that computes the quality of look and feels considering all types of objects presented to the users presented. The method applied on live websites and all the weak areas of the_website where quality improvement is required explored and presented.

Key words: Website, Assessment, Quality, Resource

\section{INTRODUCTION}

Internet and, subsequently, the Web technologies have led to heavy information exchange among the users' world over. People have access to information instantly at the least cost. Users are accessing the content presented on the web in different forms, which include images, text, graphics, video, and audio based objects. The audio and video objects are rendered in streaming, making it very difficult to judge the quality of these objects. Websites are being used increasingly for conducting e-commerce, making it more important that the websites are of high quality, especially concerning security and privacy. Websites are being used immensely for doing marketing of products. The way people go shopping changed drastically. Users' needs confidence and guarantee the correctness of the content before they start using it immensely for different purposes.
The information requirements of the users are changing rapidly. The expectations of the users for quality content are also ever-increasing. Users' satisfaction is directly proportional to the quality of the website. The importance of any website ceases if the information posted on the website is erroneous or has no relevance.

Many factors such as content, usability, completeness, structure, navigation, privacy, maintainability, security, look and feel, appearance, usability, functionality, flexibility, etc., have to be considered for assessing the quality of a web site. Every factor has to be individually should be modeled to determine its quality. Another model required for combing the quality of each factor and finally arrives at the total quality of the entire website. The quality of a factor can be computed using a subjective, objective, or quantitative approach. Subjective and objective methods provide inconsistent results and, therefore, not dependable. Few tools are in existence, and the same used for computing the quality. The tools take a holistic approach, not giving much importance to every factor. The quality of assessment is done either following a subjective or objective approach. The websites are being developed either to render static or dynamic content. Many websites developed considering a variety of content that includes videos, text, tables, animations, graphics, input/output forms leading to a complex system. Quality assessment of web sites is becoming complex due to the use of increased complexity of the websites.

Many objective or subjective methods used for computing the quality of the websites are in place. Both approaches are erroneous due to the existence of prejudice in subjective assessment and the existence of incompleteness in the objective assessment. The method proposed in the literature is biased that they are dependent on individual preferences. Some other methods based on statistical measurements do not provide direct quantitative measurement of quality, and also statistical measurements are limited to measuring the quality concerning the parameters like acceptance time, downtime, etc.

The quality requirements of a website differ from the type of user to user. Programmers who develop the website consider factors such as functionality, security, and maintainability as the most important factors that reflect the quality of the website. Regular users look at the quality of websites in terms of accuracy, ease of access, minimum navigation, more 
personalization, etc. Analytics look at the quality of web sire in terms of the quality of data accessed and stored.

A proper website must support user-specific requirements. Assessment of the quality of a website involves consideration for many factors. Most appropriate elements must be selected that match the needs of the user. However, the requirements of the users differ significantly. Therefore choosing the most appropriate set of factors is complicated. Developing web sites that ensure the quality of every element is expensive and at times, may lead to multiple web sites. It is also challenging to find a suitable model that allows the computation of the quality of every factor individually and interleaves - some factors interrelated. The condition of each element must be satisfied, and the quality of inter-dependence between the factors must also be satisfied.

Quality of some factors can be computed using subjective methods only, and some elements need to evaluate using objective methods while the majority of the factors calculated quantitatively. A composite model thus is required, which caters to computing the quality of a factor using its related suitable method.

In this paper, the quality assessment of the factor "Look and Feel" through a quantitative method presented. No technique, as such, existed in the literature that computes the quality of the element "Look and feel." The sub-factors that constitute the factor "Look and feel" and the attributes of those sub-factors presented in the paper.

\section{LITERATURE SURVEY}

An eight-item measure of web quality is generated by Jeff Sauro et al., [1] after organizing a survey conducted covering 100 web sites and 4000 users who use those web sites. They have developed a questioner contain questions that relate to four quality factors that include trust, usability, loyalty, and appearance. Their effort did not reveal any tangible quality assessment as the responses are either subjective or based on objective-based answering.

A user perspective based technique is used by Alireza Habibi et al., [2] for developing a computational method that is reliable and consistent. The determined four factors for computing quality of the website that includes content, appearance, adequacy, which were found later as inadequate. They went on to define the element "Appearance" as the measure of visual attractiveness of a website that includes colors, fonts, and many multimedia based objects.

Maria Shusanti Febrianti et al., [3] have conducted in-depth interactions on dimension stacking and 14-grain questions. 'Webqual 3.0" was designed by observing in 3 areas, one of which is the usability of human-computer interaction. Usability is a quality related to site design, for example, the appearance, the more natural way of user navigation, and visualization of the user.
Quality of a website defined by Mohammed Alshehri et al., [4] as the positive evaluation of the features of the website by the users, and that ensures the fulfillment of the user requirements and also that it reflects the overall excellence of the website. The factors that include appearance, web content, and technical adequacy identified as the most critical factors which are proved to be in-adequate assessment.

A quality scale designed by Bernd F. Reitsamer et al., [5] used for computing the quality of the website considering four factors. He has used the scale to calculate the quality of their University site. He has not considered the functionality related to service interaction, support for transactions, transaction quality, safety, and has only found the quality of content, and appearance which are not adequate factors for computing the quality of the websites.

The customer's support for the websites and their behavior loyalty is tested by Sanjit Kumar Roy et al., [6] using an empirical test that is built to test a composite E-commerce model. In the composite model, he has considered six factors for computing the quality of online retail shops, which include updated news, appearance, information, navigation, organization, and interactivity with the users. The authors have considered look, feel, and overall appearance of the website into account.

A large study is conducted by Brendan Spillane et al., [7] to determine the impact of visual appearance on the perception of the users and found that both aspects positively correlated. However, the study is limited to microscopic visualization.

A study of the quality of the website related to apparel retailers is conducted by Romana Garma et al., [8] through the use of WebQual instruments. Six factors considered include fitness of information to a given task, appearance innovativeness, trust, emotional appeal, type of transactions supported, and response time. They have studied whether web appearance is visually appealing and pleasing in addition to studying the ease of using the website.

A high-quality educational website is developed by WingShui $\mathrm{Ng}$ et al., [9], keeping in view the Pre-service teachers. He considered color, fonts, graphics, multimedia elements, and topography as the most critical factors that must be supported such that the website attracts many pre-service teachers. However, no correlation as such established.

The differences between the expectation of the users (considering five different factors) and perceptions of the users used for developing a quality assessment model by Davide Di Fatta et al., [10]. Appearance is one of those five factors about which the expectation of users is sought and built into a model called SERVQUALmodel. They have concluded that the users will be satisfied if clear details related to equipment, physical facilities, and communicating materials provided on the website.

The context of B2C eCommerce is studied by Euijin Kim et al., [11] and developed a model used for mediating trust of 
the customer's purchase intention concerning website quality. He has predicted that web site quality determined in terms of appearance and functionality affects the initial trust of the customers. The initial belief affects the purchase intentions of the customers subsequently.

Rafikul Islam et al., [12] have developed a model to evaluate the usability and extent usefulness of websites. This model considers the following seven factors: screen appearance, content, accessibility, navigation, media use, interactivity, and consistency.

Tamer Adel Saleh Alajrami et al., [13] presented a paper on The impact of the Facebook website quality on a user's perceived attitude, intention, and loyalty among students of UTM. His study found that General Content Quality, Appearance Quality, and Reputation significantly influenced an individual's perspective. Also, both of Appearance Quality and Attitude influenced an individual's intention to use the Facebook website.

Xiuyuan Gao et al., [14] presented a paper on The Influence of Mobile Website Quality on Consumer Satisfaction and Behavior. In the measurement of website design quality, he referred to the web site's navigation, appearance, and a sense of competency.

Dawn G. Gregg. Steven Walczak et al., [15] presented a paper on The relationship between website quality, trust, and price premiums at online auctions. His website quality research focused on traditional businesses, and it is not clear whether the benefits of website quality will have as significant an impact in a domain like online auctions where vendors share a single market space (e.g., eBay) and can only control the appearance and content of a small portion of a web page.

Sandra Andrs Maria Correia Loureiro [16] presented a paper on The Role of Website Quality on PAD, Attitude, and Intentions to Visit and Recommend Island Destination. He measured Internet travel advertising(ad) content design using a group of seven items covering animation effects, position and size, pictures and texts in ads, exposure frequency and length, advertising creativity, ad interactivity, and the whole appearance.

Kholoud Al-Qeisi et al., [17] indicated that the technical, general content and appearance dimensions of a website are most important for users. He implies that improvements to the appearance of a website should enhance the overall evaluation of the site, leading to higher usage intentions. Appearance refers to characteristics such as attractiveness, organization, proper use of fonts, colors, and proper use of multimedia.

Maliha Zaman et al., [18] presented a paper on the Quality of Public Sector Website and its Impact on Citizen Involvement. He defined Appearance as the visual design and the layout of the PSW. He determined that many factors need consideration for evaluating the appearance, such as resolution and color contrast.

Vassilis S. Moustakis [19] presented Website quality assessment criteria. He determined that Appearance and Multimedia capture aspects that relate to the site's "look and feel" with particular emphasis in state of the art graphics and multimedia artifacts.

Several approaches presented that lead to implementing personalized user interface [20], Enhancing the performance of search engines [21][22], and selection of the user interface dynamically for displaying mined results[23] that all lead to improvement of the quality of the web sites.

An architectural approach proposed by Sastry et al.[24] is useful for assessing the quality of a WEB site from a different perspective that includes usability of the WEB sites, quality of content, quality from the standpoint of completeness, [25][26][27].

\section{INVESTIGATIONS AND FINDINGS}

The effective use of WEB sites is primarily dependent on the look and feel of the WEB and the quality with which the look and feel of the WEB site developed. Youngsters these days want the very high-level look and feel if not they tend to ignore the website even if the content hosted on the WEB is vibrant and valuable.

The look and feel of the WEB site must be in line with the context in which the content displayed. Every WEB page shows the content that has the context. A web site, as such, developed in terms of a set of resource files that has code in it developed using the markup or scripting Languages. The content of the resources data is displayed to the end-user by a WEB browser - the User interface used for showing the results coded within the resource files itself.

The look and feel of the display are dependent on various aspects that include Fonts used; Text displayed, back Ground colors, foreground colors, representation of different types of menus systems and the display of multi-media objects that include Images, Videos, and Audio files and different kinds of animations included into the display outputs. The type of look and feel of various objects included in the display is dependent on the context in which the display made. The contexts used for developing a web site can be re-identified, and the standard look and feel profile used can be attached to the contexts.

In the student's management system, the typical contexts used include Registration, Fee Payment, Examinations, Academics, research, events, etc. The look and feel for each of the contexts in terms include different kinds of objects. The quality of each display is much dependent on the type of objects used and the characteristics used for making those objects. One can map the context, different objects included in the context, and characteristic values of the objects. 


\section{Building Expert system}

An expert system can be built to derive Characteristic values of either characteristics or sub-characteristics of different types of objects that reflect the look and feel of the WEB sites. An intelligent system built for acquiring the expert system as the WEB site is on use by different users over some time. Alternatively, experts in the filed can define characteristic values.

Table 1 shows the mapping of the context to different objects and the characteristic values of those objects considering a student management system related web site as defined by the experts. The particular values can be updated as the experts gain the experience.

The quality of a WEB page is expected to be $100 \%$ if the above mentioned characteristic values are used to build the display having found the context around which the WEB sites built.

\section{Finding the context of a WEB page:-}

The most crucial issue is to find the context of every WEB page of a WEB site. Finding context is the most complicated issue. The context of every page can be manually defined and or intelligently fund based on the file name or the content enclosed into the markup code. One way to find the context is to find the repeated snippets, and the most commonly used snippet used as the context. A snippet table is used to generate the context. A context derived after assigning a minimum threshold value to each snippet. Table 2 shows the Snippets considered as contexts. From Table 2 It can be found that restorations, Academics, Research, events, and fee payment found in contexts. The context is the most considerable snippet value selected as a context.

\section{Classifying the resource files as per contexts}

There can be several resource files with the same context. A context recognized by grouping the resource files. The resource files grouped as the context. Table 3 shows the Groping of the resource files based on the context.

\section{Processing the Resource files}

Processing the resource files is the next step for determining the characteristic values for each of the Objects contained in the resource files and then computing the quality of the Objects concerning a context.

\section{Algorithm}

For each context

(

For each of the resource file in the context

For each type of the object

(

\author{
Find the objects \\ For each object find the characteristic value \\ from tags and attributes \\ Compare the characteristic values fetched \\ standard expert system-defined values \\ Find the variations \\ Find the quality of the object by subtracting the \\ deviation from $100 \%$ value \\ The overall quality assessed by multiplying the \\ object quality with the overall quality

) ( )

Computing the variations and quality of the Objects:-

The objects contained in web pages belong to the same context found. For example, let the context be registration. Three html files are related to the context "registration." The objects contained in these web pages can be as under, as shown in Table 4.

\section{DISCUSSION AND EXPERIMENTAL RESULTS}

The algorithm applied to standard WEB sites and the results obtained for a particular context shown in Table 5. For the context "Registrations," three resource files Traced, which include the html files "Registrations," "priorities," and "subsections." Experimental results related to the "registration" resource file shown in Table 5. The quality of the WEB site just considering the registration is either the product of the quality computations is the minimum of the quality values obtained for different characteristics, which in the example case is 0.33 .

\section{CONCLUSION}

Websites are developed using a variety of objects, which include text, colors, images, videos, and graphics. The look and feel of the websites must be great; if not, the users will not like to surf the websites, and the importance of the web sites will be last in spite of rendering high-quality content. Assessing the quality of Websites is quite complicated as many intricate issues are involved, especially involving too many aspects that include colors, size, resolutions, inverse, and reverse videos, etc.

The Look and feel of web site vary from user to user. Many websites are moving towards personalizing the web sites so that the look and feel of the web sites presented as per the user's desire and liking. However, users need to know the way to improve the look and feel as there are many options and variations. The users need to see the quality of the look and feel and also need to know the areas where quality is to be improved. Subjective and objective methods do not reflect the quality of the websites as it is difficult to make human judgments when variety and vast options exist.

In this paper, an interactive quantitative assessment of the quality of the websites presented, which can be used by the 
user for quality assessment of different aspects and then interactively define the kind of quality improvement required when weak areas of the website are spotted out.

\section{REFERENCES}

1. Jeff Sauro, SUPR-Q: A comprehensive measure of the quality of the website user experience.\&quot; Journal of usability studies 10 , no. 2 (2015): 68-86.

https://doi.org/10.5539/ass.v10n11p210

2. Habibi, Alireza, Sahar Golkari Hagh, Mehdi Hooshmand Bahabadi, Sharareh Shahidi Hamedani, Norjaya Mohd Yasin, and Nor Asiah Omar,\&quot; Brand Personality Moderating Effect on Relationship between Website Quality and Online Trust: Malaysian Online Environment Context.\&quot; Asian Social Science10, no. 11, (2014): 210.

3. Ferranti, Maria Shusanti,\&quot; Indonesian Puslit (Centre Of IT Solution) Website Analysis Using Webqual For Measuring Website Quality.\&quot; In International Conference on Engineering and Technology Development (ICETD). 2013.

4. Alshehri, Mohammed, Steve Drew, Thamer AlHussain, and Rayed Alghamdi,\&quot; The Effects of Website Quality on Adoption of E-Government Service: AnEmpirical Study Applying UTAUT Model Using SEM.\&quot; arXiv preprint ar X iv:1211.2410 (2012).

5. Reitsamer, Bernd Frederik, Andreas Kaschig, Tim Dominique Heinz, and Nicola E. Stokburger-Sauer, The Effects of Website Quality Perception on Users' Responses-A Multidisciplinary Approach.\&quot; (2014).

6. Sanjit Kumar Roy, Butaney, Gul,\&quot; ECustomer Relative Share of Mind: The Role of Website Quality Dimensions, Site-customers' Attitudes and E-Satisfaction.\&quot;

7. Spillane, Brendan, Séamus Lawless, and Vincent Wade,\&quot; Increasing and Decreasing Perceived Bias by Distorting the Quality of News Website Design.\&quot;

8. Garma, Romana, and Olga Junek,\&quot; Evaluating Website quality of Tourism Websites: A Study of Australian and Malaysian Consumers.\&quot; CAUTHE 2006: To the City and Beyond (2006): 1745.

9. $\mathrm{Ng}$, Wing-Shui,\&quot; Critical design factors of developing a high-quality educational website: perspectives of pre-service teachers.\&quot; Issues in Informing Science \&amp; Information Technology 11(2014): 101-114. https://doi.org/10.28945/1983

10. Moretti, Andrea, Michela Cesarina Mason, and Davide Di Fatta,\&quot; Measuring website quality: theoretical framework and practical implications for the agro-food sector in the European Alpine area.\&quot; International Journal of Electronic Marketing and Retailing 8, no. 3 (2017): 212-231.
https://doi.org/10.1504/IJEMR.2017.10007090

11. Kim, Euijin, and Rui Zhang,\&quot; Mediating role of initial trust on the relationship between website quality and purchase intention.\&quot; SAIS 2014 Proceedings (2014): 1 Y6.

12. Islam, Rafikul, Mohiuddin Ahmed, and Masliza $\mathrm{Hj}$ Alias,\&quot; Application of Quality Function Deployment in redesigning the website: a case study on TV3.\&quot; International Journal of Business Information Systems 2, no. 2 (2006): 195-216. https://doi.org/10.1504/IJBIS.2007.011619

13. Alajrami, Tamer Adel Saleh,\&quot; The Impact of the Facebook Website Quality on Users Perceived Attitude, Intention, and Loyalty Among Students of UTM.\&quot; Ph.D. diss., Universiti

Teknologi Malaysia, 2013.

14. Gao, Xiuyuan, The Influence of Mobile Website Quality on Consumer Satisfaction and Behavior.\&quot; (2013).

15. Gregg, Dawn G., and Steven Walczak,\&quot; The relationship between website quality, trust and price premiums at online auctions.\&quot; Electronic Commerce Research 10, no. 1 (2010): 1-25.

16. Loureiro, Sandra Maria Correia,\&quot; The role of website quality on PAD, attitude and intentions to visit and recommend island destination.\&quot; International Journal of Tourism Research 17, no. 6 (2015): 545-554.

17. Al-Qeisi, Kholoud, Charles Dennis, Eleftherios Alamanos, and Chanaka Jayawardhena, \&quot; Website design quality and usage behavior: Unified Theory of Acceptance and Use of Technology.\&quot; Journal of Business Research 67, no. 11 (2014): 2282-2290. https://doi.org/10.1016/j.jbusres.2014.06.016

18. Zaman, Maliha., Quality of public sector website and its impact on citizen involvement, "https://journals.sagepub.com," (2010)

19. Moustakis, Vassilis, Charalambos Litos, Andreas Dalivigas, and Loukas Tsironis,\&quot; Website Quality Assessment Criteria.\&quot; IQ 5 (2004): 59-73.

20. Jammalamadaka, S.B. Duvvuri, B.K.K. Jammalamadaka, K.R.S. Priyanka, J.H., Automating WEB interface about user behavior, Advances in Intelligent Systems and Computing, 2019, 815, pp. 91-102

21. Sastry, J.K.R. Chittibomma, C.S. Alla, T.M.R, Enhancing the performance of search engines based heap-based data file and hash-based indexing file, International Journal of Engineering and Technology(UAE), 2018, 7, pp. 372-375

22. Sastry, J.K.R. Sri Harsha Vamsi, M. Srinivas, R. Yeshwanth, G., Optimizing performance of search engines based on user behavior, International Journal of Engineering and Technology (UAE), 2018, 7, pp. 359-362

23. Sastry, J.K.R. Jyothsna Sai Sree, M. Mani Dedeepya, T. Kamesh, D.B.K., On selection of a user interface dynamically for displaying data 
B. Vishnu Priya et al., International Journal of Emerging Trends in Engineering Research, 7(10), October 2019, 360 - 375

mined results, ARPN Journal of Engineering and Applied Sciences, 2017, 12(11), pp. 3561-3572

24. Kamesh D.B.K., Sasi Bhanu J., Sastry J.K.R, An architectural approach for assessing the quality of web sites, ARPN Journal of Engineering and Applied Sciences, 2018, 13(15), pp, 4503-451

25. Sastry, J.K.R. Sreenidhi, N. Sasidhar, K, Quantifying quality of WEB-site based on usability, International Journal of Engineering and Technology(UAE), 2018, 7, pp. 320-322

https://doi.org/10.14419/ijet.v7i2.7.10606
26. Venkata Raghavarao, Y. Sasidhar, K. Sastry, J.K.R., Chandra Prakash, V. Quantifying quality of WEB sites based on content, International Journal of Engineering and Technology(UAE), 2018, 7(2), pp. 138-141

27. Bhanu, J.S. Kamesh, D.B.K. Sastry, J.K.R., Assessing completeness of a WEB site from Quality Perspective, International Journal of Electrical and Computer Engineering, 2019, 9(6), pp. 5596-5603 
B. Vishnu Priya et al., International Journal of Emerging Trends in Engineering Research, 7(10), October 2019, 360 - 375

Context 1: Registration:-

Table 1: Expert System - Look and Feel of the WEB sites

\begin{tabular}{|c|c|c|c|}
\hline Object & Characteristic & Sub Characteristics & Characteristic value \\
\hline \multirow{7}{*}{ Font } & Type & & Time New Roman \\
\hline & Style & & Regular \\
\hline & Size & & 11 \\
\hline & \multirow{3}{*}{ Colour } & Red & 40 \\
\hline & & Yellow & 40 \\
\hline & & Blue & 40 \\
\hline & Case & & Sentence \\
\hline \multirow{4}{*}{ Text } & Paragraph Margin & & 6 \\
\hline & Front space & & 6 \\
\hline & BackSpace & & 6 \\
\hline & Style & & Regular \\
\hline \multirow{5}{*}{ Tables } & Number of columns & & 4 \\
\hline & Number of rows & & 20 \\
\hline & \multirow[t]{3}{*}{ Row Heading Color } & Red & 45 \\
\hline & & Yellow & 45 \\
\hline & & Blue & 45 \\
\hline \multirow{14}{*}{ Tables } & \multirow{3}{*}{ Column Heading Color } & Red & 50 \\
\hline & & Yellow & 50 \\
\hline & & Blue & 50 \\
\hline & Font Type & Regular & Regular \\
\hline & Font Style & Bold & Bold \\
\hline & Font Size & 11 & 11 \\
\hline & \multirow[t]{4}{*}{ Font Color } & Red & 60 \\
\hline & & Yellow & 60 \\
\hline & & Blue & 60 \\
\hline & & Case & Regular \\
\hline & \multirow[t]{4}{*}{ Text } & Paragraph Margin & 6 \\
\hline & & Front space & 6 \\
\hline & & BackSpace & 6 \\
\hline & & Style & Regular \\
\hline \multirow{8}{*}{ Menus } & Tree Menu & Number of Sub-menus & 3 \\
\hline & File Menu & $\begin{array}{l}\text { Number of Listed } \\
\text { objects }\end{array}$ & 20 \\
\hline & TAB Menu & Number & 20 \\
\hline & Tab Object Menu & Number & 10 \\
\hline & \multirow[t]{3}{*}{ Bottom Bar color } & Red & 60 \\
\hline & & Yellow & 60 \\
\hline & & Blue & 60 \\
\hline & Bottom Bar Objects & Number & 20 \\
\hline \multirow{3}{*}{ Background Colors } & Red & 65 & \\
\hline & YELLOW & 65 & \\
\hline & Blue & 65 & \\
\hline \multirow{3}{*}{ Foreground Colors } & Red & 40 & \\
\hline & YELLOW & 40 & \\
\hline & Blue & 40 & \\
\hline
\end{tabular}


B. Vishnu Priya et al., International Journal of Emerging Trends in Engineering Research, 7(10), October 2019, 360 - 375

\begin{tabular}{|l|l|c|c|}
\hline \multirow{5}{*}{ Object } & \multicolumn{1}{|c|}{ Characteristic } & Sub Characteristics & Characteristic value \\
\hline \multirow{5}{*}{ Images } & Width in Pixel & 1100 & \\
\cline { 2 - 4 } & Height in Pixel & 1100 & 40 \\
\cline { 2 - 4 } & Colors & Red & 40 \\
\cline { 3 - 4 } & & YELLOW & 40 \\
\cline { 2 - 4 } & & Blue & \\
\hline \multirow{5}{*}{ Videos } & Width in Pixel & 1100 & 45 \\
\cline { 2 - 4 } & Height in Pixel & 1100 & 45 \\
\cline { 2 - 4 } & Colors & Red & 45 \\
\cline { 2 - 4 } & & YELLOW & \\
\cline { 2 - 4 } & & Blue & \\
\hline Audio & Frames per second & 1000 & \\
\hline
\end{tabular}

Context 2: Fee Payment:-

\begin{tabular}{|c|c|c|c|}
\hline Object & Characteristic & Sub Characteristics & Characteristic value \\
\hline \multirow{7}{*}{ Font } & Type & & Time New Roman \\
\hline & Style & & Regular \\
\hline & Size & & 11 \\
\hline & \multirow{3}{*}{ Color } & Red & 40 \\
\hline & & Yellow & 40 \\
\hline & & Blue & 40 \\
\hline & Case & & Sentence \\
\hline \multirow[t]{4}{*}{ Text } & Paragraph Margin & & 6 \\
\hline & Front space & & 6 \\
\hline & BackSpace & & 6 \\
\hline & Style & & Regular \\
\hline \multirow[t]{5}{*}{ Tables } & Number of columns & & 4 \\
\hline & Number of rows & & 20 \\
\hline & \multirow[t]{3}{*}{ Row Heading Color } & Red & 45 \\
\hline & & Yellow & 45 \\
\hline & & Blue & 45 \\
\hline \multirow{14}{*}{ Tables } & \multirow{3}{*}{ Column Heading Color } & Red & 50 \\
\hline & & Yellow & 50 \\
\hline & & Blue & 50 \\
\hline & Font Type & Regular & Regular \\
\hline & Font Style & Bold & Bold \\
\hline & Font Size & 11 & 11 \\
\hline & \multirow[t]{4}{*}{ Font Color } & Red & 60 \\
\hline & & Yellow & 60 \\
\hline & & Blue & 60 \\
\hline & & Case & Regular \\
\hline & \multirow[t]{4}{*}{ Text } & Paragraph Margin & 6 \\
\hline & & Front space & 6 \\
\hline & & BackSpace & 6 \\
\hline & & Style & Regular \\
\hline
\end{tabular}


B. Vishnu Priya et al., International Journal of Emerging Trends in Engineering Research, 7(10), October 2019, 360 - 375

\begin{tabular}{|c|c|c|c|}
\hline Object & Characteristic & Sub Characteristics & Characteristic value \\
\hline \multirow[t]{8}{*}{ Menus } & Tree Menu & Number of Sub-menus & 3 \\
\hline & File Menu & 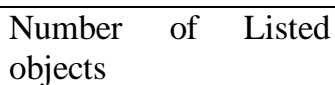 & 20 \\
\hline & TAB Menu & Number & 20 \\
\hline & Tab Object Menu & Number & 10 \\
\hline & \multirow[t]{3}{*}{ Bottom Bar color } & Red & 60 \\
\hline & & Yellow & 60 \\
\hline & & Blue & 60 \\
\hline & Bottom Bar Objects & Number & 20 \\
\hline \multirow[t]{3}{*}{ Background Colors } & Red & 65 & \\
\hline & YELLOW & 65 & \\
\hline & Blue & 65 & \\
\hline \multirow[t]{3}{*}{ Foreground Colors } & Red & 40 & \\
\hline & YELLOW & 40 & \\
\hline & Blue & 40 & \\
\hline \multirow[t]{5}{*}{ Images } & Width in Pixel & 1100 & \\
\hline & Height in Pixel & 1100 & \\
\hline & \multirow[t]{3}{*}{ Colors } & Red & 40 \\
\hline & & YELLOW & 40 \\
\hline & & Blue & 40 \\
\hline object & Characteristic & Sub Characteristics & Characteristic value \\
\hline \multirow[t]{6}{*}{ Videos } & Width in Pixel & 1100 & \\
\hline & Height in Pixel & 1100 & \\
\hline & \multirow[t]{3}{*}{ Colors } & Red & 45 \\
\hline & & YELLOW & 45 \\
\hline & & Blue & 45 \\
\hline & Frames per second & 10 & \\
\hline Audio & Decibels & 1000 & \\
\hline
\end{tabular}

Context 3: Academics:-

\begin{tabular}{|c|c|c|c|}
\hline object & Characteristic & Sub Characteristics & Characteristic value \\
\hline \multirow{7}{*}{ Font } & Type & & Time New Roman \\
\hline & Style & & Regular \\
\hline & Size & & 11 \\
\hline & \multirow{3}{*}{ Color } & Red & 40 \\
\hline & & Yellow & 40 \\
\hline & & Blue & 40 \\
\hline & Case & & Sentence \\
\hline \multirow[t]{4}{*}{ Text } & Paragraph Margin & & 6 \\
\hline & Front space & & 6 \\
\hline & BackSpace & & 6 \\
\hline & Style & & Regular \\
\hline \multirow[t]{5}{*}{ Tables } & Number of columns & & 4 \\
\hline & Number of rows & & 20 \\
\hline & \multirow[t]{3}{*}{ Row Heading Color } & Red & 45 \\
\hline & & Yellow & 45 \\
\hline & & Blue & 45 \\
\hline
\end{tabular}


B. Vishnu Priya et al., International Journal of Emerging Trends in Engineering Research, 7(10), October 2019, 360 - 375

\begin{tabular}{|c|c|c|c|}
\hline object & Characteristic & Sub Characteristics & Characteristic value \\
\hline \multirow{14}{*}{ Tables } & \multirow{3}{*}{ Column Heading Color } & Red & 50 \\
\hline & & Yellow & 50 \\
\hline & & Blue & 50 \\
\hline & Font Type & Regular & Regular \\
\hline & Font Style & Bold & Bold \\
\hline & Font Size & 11 & 11 \\
\hline & \multirow[t]{4}{*}{ Font Color } & Red & 60 \\
\hline & & Yellow & 60 \\
\hline & & Blue & 60 \\
\hline & & Case & Regular \\
\hline & \multirow[t]{4}{*}{ Text } & Paragraph Margin & 6 \\
\hline & & Front space & 6 \\
\hline & & BackSpace & 6 \\
\hline & & Style & Regular \\
\hline \multirow[t]{8}{*}{ Menus } & Tree Menu & Number of Sub-menus & 3 \\
\hline & File Menu & $\begin{array}{lll}\begin{array}{l}\text { Number } \\
\text { objects }\end{array} & \text { of Listed } \\
\end{array}$ & 20 \\
\hline & TAB Menu & Number & 20 \\
\hline & Tab Object Menu & Number & 10 \\
\hline & \multirow[t]{3}{*}{ Bottom Bar color } & Red & 60 \\
\hline & & Yellow & 60 \\
\hline & & Blue & 60 \\
\hline & Bottom Bar Objects & Number & 20 \\
\hline \multirow[t]{3}{*}{ Background Colors } & Red & 65 & \\
\hline & YELLOW & 65 & \\
\hline & Blue & 65 & \\
\hline \multirow[t]{3}{*}{ Foreground Colors } & Red & 40 & \\
\hline & YELLOW & 40 & \\
\hline & Blue & 40 & \\
\hline \multirow[t]{5}{*}{ Images } & Width in Pixel & 1100 & \\
\hline & Height in Pixel & 1100 & \\
\hline & \multirow[t]{3}{*}{ Colors } & Red & 40 \\
\hline & & YELLOW & 40 \\
\hline & & Blue & 40 \\
\hline \multirow[t]{6}{*}{ Videos } & Width in Pixel & 1100 & \\
\hline & Height in Pixel & 1100 & \\
\hline & \multirow[t]{3}{*}{ Colors } & Red & 45 \\
\hline & & YELLOW & 45 \\
\hline & & Blue & 45 \\
\hline & Frames per second & 10 & \\
\hline Audio & Decibels & 1000 & \\
\hline
\end{tabular}


B. Vishnu Priya et al., International Journal of Emerging Trends in Engineering Research, 7(10), October 2019, 360 - 375

\section{Context 4: Research}

\begin{tabular}{|c|c|c|c|}
\hline Object & Characteristic & Sub Characteristics & Characteristic value \\
\hline \multirow{7}{*}{ Font } & Type & & Time New Roman \\
\hline & Style & & Regular \\
\hline & Size & & 11 \\
\hline & \multirow{3}{*}{ Color } & Red & 40 \\
\hline & & Yellow & 40 \\
\hline & & Blue & 40 \\
\hline & Case & & Sentence \\
\hline \multirow[t]{4}{*}{ Text } & Paragraph Margin & & 6 \\
\hline & Front space & & 6 \\
\hline & BackSpace & & 6 \\
\hline & Style & & Regular \\
\hline \multirow[t]{5}{*}{ Tables } & Number of columns & & 4 \\
\hline & Number of rows & & 20 \\
\hline & \multirow[t]{3}{*}{ Row Heading Color } & Red & 45 \\
\hline & & Yellow & 45 \\
\hline & & Blue & 45 \\
\hline \multirow{14}{*}{ Tables } & \multirow{3}{*}{ Column Heading Color } & Red & 50 \\
\hline & & Yellow & 50 \\
\hline & & Blue & 50 \\
\hline & Font Type & Regular & Regular \\
\hline & Font Style & Bold & Bold \\
\hline & Font Size & 11 & 11 \\
\hline & \multirow[t]{4}{*}{ Font Colour } & Red & 60 \\
\hline & & Yellow & 60 \\
\hline & & Blue & 60 \\
\hline & & Case & Regular \\
\hline & \multirow[t]{4}{*}{ Text } & Paragraph Margin & 6 \\
\hline & & Front space & 6 \\
\hline & & BackSpace & 6 \\
\hline & & Style & Regular \\
\hline \multirow[t]{8}{*}{ Menus } & Tree Menu & Number of Sub-menus & 3 \\
\hline & File Menu & $\begin{array}{l}\begin{array}{l}\text { Number } \\
\text { objects }\end{array} \\
\text { of Listed }\end{array}$ & 20 \\
\hline & TAB Menu & Number & 20 \\
\hline & Tab Object Menu & Number & 10 \\
\hline & \multirow{3}{*}{ Bottom Bar color } & Red & 60 \\
\hline & & Yellow & 60 \\
\hline & & Blue & 60 \\
\hline & Bottom Bar Objects & Number & 20 \\
\hline \multirow{3}{*}{ Background Colors } & Red & 65 & \\
\hline & YELLOW & 65 & \\
\hline & Blue & 65 & \\
\hline \multirow[t]{3}{*}{ Foreground Colors } & Red & 40 & \\
\hline & YELLOW & 40 & \\
\hline & Blue & 40 & \\
\hline \multirow[t]{5}{*}{ Images } & Width in Pixel & 1100 & \\
\hline & Height in Pixel & 1100 & \\
\hline & \multirow[t]{3}{*}{ Colors } & Red & 40 \\
\hline & & YELLOW & 40 \\
\hline & & Blue & 40 \\
\hline
\end{tabular}


B. Vishnu Priya et al., International Journal of Emerging Trends in Engineering Research, 7(10), October 2019, 360 - 375

\begin{tabular}{|l|l|l|c|}
\hline \multicolumn{1}{|c|}{ Object } & \multicolumn{1}{|c|}{ Characteristic } & \multicolumn{1}{|c|}{ Sub Characteristics } & Characteristic value \\
\hline \multirow{4}{*}{ Videos } & Width in Pixel & 1100 & \\
\cline { 2 - 4 } & Height in Pixel & \multicolumn{1}{|c|}{1100} & 45 \\
\cline { 2 - 4 } & Colors & Red & 45 \\
\cline { 2 - 4 } & & YELLOW & 45 \\
\cline { 2 - 4 } & & Blue & \\
\cline { 2 - 4 } & Frames per second & 10 & \\
\hline Audio & Decibels & \multicolumn{1}{|c|}{1000} & \\
\hline
\end{tabular}

\section{Context 5: Events}

\begin{tabular}{|c|c|c|c|}
\hline object & Characteristic & Sub Characteristics & Characteristic value \\
\hline \multirow{7}{*}{ Font } & Type & & Time New Roman \\
\hline & Style & & Regular \\
\hline & Size & & 11 \\
\hline & \multirow{3}{*}{ Color } & Red & 40 \\
\hline & & Yellow & 40 \\
\hline & & Blue & 40 \\
\hline & Case & & Sentence \\
\hline \multirow[t]{4}{*}{ Text } & Paragraph Margin & & 6 \\
\hline & Front space & & 6 \\
\hline & BackSpace & & 6 \\
\hline & Style & & Regular \\
\hline \multirow[t]{5}{*}{ Tables } & Number of columns & & 4 \\
\hline & Number of rows & & 20 \\
\hline & \multirow[t]{3}{*}{ Row Heading Color } & Red & 45 \\
\hline & & Yellow & 45 \\
\hline & & Blue & 45 \\
\hline \multirow{14}{*}{ Tables } & \multirow{3}{*}{ Column Heading Color } & Red & 50 \\
\hline & & Yellow & 50 \\
\hline & & Blue & 50 \\
\hline & Font Type & Regular & Regular \\
\hline & Font Style & Bold & Bold \\
\hline & Font Size & 11 & 11 \\
\hline & Font Color & Red & 60 \\
\hline & & Yellow & 60 \\
\hline & & Blue & 60 \\
\hline & & Case & Regular \\
\hline & Text & Paragraph Margin & 6 \\
\hline & & Front space & 6 \\
\hline & & BackSpace & 6 \\
\hline & & Style & Regular \\
\hline Menus & Tree Menu & Number of Sub-menus & 3 \\
\hline & File Menu & $\begin{array}{l}\text { Number of Listed } \\
\text { objects }\end{array}$ & 20 \\
\hline & TAB Menu & Number & 20 \\
\hline & Tab Object Menu & Number & 10 \\
\hline & Bottom Bar color & Red & 60 \\
\hline & & Yellow & 60 \\
\hline & & Blue & 60 \\
\hline & Bottom Bar Objects & Number & 20 \\
\hline
\end{tabular}


B. Vishnu Priya et al., International Journal of Emerging Trends in Engineering Research, 7(10), October 2019, 360 - 375

\begin{tabular}{|c|c|c|c|}
\hline object & Characteristic & Sub Characteristics & Characteristic value \\
\hline \multirow[t]{3}{*}{ Background Colors } & Red & 65 & \\
\hline & YELLOW & 65 & \\
\hline & Blue & 65 & \\
\hline \multirow[t]{3}{*}{ Foreground Colors } & Red & 40 & \\
\hline & YELLOW & 40 & \\
\hline & Blue & 40 & \\
\hline \multirow[t]{5}{*}{ Images } & Width in Pixel & 1100 & \\
\hline & Height in Pixel & 1100 & \\
\hline & \multirow[t]{3}{*}{ Colors } & Red & 40 \\
\hline & & YELLOW & 40 \\
\hline & & Blue & 40 \\
\hline \multirow[t]{6}{*}{ Videos } & Width in Pixel & 1100 & \\
\hline & Height in Pixel & 1100 & \\
\hline & \multirow[t]{3}{*}{ Colors } & Red & 45 \\
\hline & & YELLOW & 45 \\
\hline & & Blue & 45 \\
\hline & Frames per second & 10 & \\
\hline Audio & Decibels & 1000 & \\
\hline
\end{tabular}

Table 2 :Context Identification

\begin{tabular}{|c|c|c|c|}
\hline $\begin{array}{c}\text { Serial } \\
\text { Number }\end{array}$ & WEB Page Name & Snippet & Snippet occurrence value \\
\hline 1. & \multirow{3}{*}{ Registratins.html } & Registrations & 4 \\
\hline 2. & & Subject & 2 \\
\hline 3. & & Priority & 1 \\
\hline 4. & \multirow{3}{*}{ Feepaymnet.html } & Fee payment & 4 \\
\hline 5. & & Receipt & 1 \\
\hline 6. & & Challan & 1 \\
\hline 7. & \multirow{3}{*}{ Academics. Html } & Lesson plan & 2 \\
\hline 8. & & Course delivery & 2 \\
\hline 9. & & Academics & 6 \\
\hline 10. & \multirow{3}{*}{ Research.html } & Sponsored & 6 \\
\hline 11. & & Academic research & 6 \\
\hline 12. & & Research & 10 \\
\hline 13. & \multirow{4}{*}{ Events.html } & Cultural & 8 \\
\hline 14. & & sports & 8 \\
\hline 15. & & Alumni & 5 \\
\hline 16. & & Event & 22 \\
\hline
\end{tabular}


B. Vishnu Priya et al., International Journal of Emerging Trends in Engineering Research, 7(10), October 2019, 360 - 375

Table 3 : Classifying the Resource file as per the contexts

\begin{tabular}{|c|c|c|}
\hline $\begin{array}{c}\text { Serial } \\
\text { Number }\end{array}$ & Context & Resource files \\
\hline \multirow[t]{3}{*}{1.} & \multirow{3}{*}{ Registrations } & Registrations.html \\
\hline & & Priorities. Html \\
\hline & & SubSections.html \\
\hline \multirow[t]{3}{*}{2.} & \multirow{3}{*}{ Fee Payments } & Challan.html \\
\hline & & Nefttranfer.html \\
\hline & & Onlinetranfer.html \\
\hline \multirow[t]{3}{*}{3.} & \multirow{3}{*}{ Academics } & Internalexams.html \\
\hline & & TimeTables.html \\
\hline & & Facultyllocations.html \\
\hline \multirow[t]{3}{*}{4.} & \multirow{3}{*}{ Research } & Paperspublsihed.html \\
\hline & & Sponsoredprojects.html \\
\hline & & Internalprojects.html \\
\hline \multirow[t]{3}{*}{5.} & \multirow{3}{*}{ Events } & Cultutral.html \\
\hline & & Sports.html \\
\hline & & Alumniactivities.html \\
\hline
\end{tabular}

Table 4: Object identification context-wise and object wise

\begin{tabular}{|c|c|c|c|}
\hline $\begin{array}{c}\text { Serial } \\
\text { number }\end{array}$ & Resource files & Type of object & Number of Objects \\
\hline \multirow{8}{*}{1} & \multirow{8}{*}{ Registrations.html } & font & 1 \\
\hline & & Text & 1 \\
\hline & & Back Ground Color & 1 \\
\hline & & Fore Ground color & 1 \\
\hline & & Tables & 1 \\
\hline & & Images & 1 \\
\hline & & Videos & 1 \\
\hline & & Audios & 1 \\
\hline \multirow{8}{*}{2} & \multirow{8}{*}{ Priorities. html } & font & 1 \\
\hline & & Text & 1 \\
\hline & & Back Ground Color & 1 \\
\hline & & Fore Ground color & 1 \\
\hline & & Tables & 1 \\
\hline & & Images & 1 \\
\hline & & Videos & 1 \\
\hline & & Audios & 1 \\
\hline \multirow{8}{*}{3} & \multirow{8}{*}{ SubSections.html } & font & 1 \\
\hline & & Text & 1 \\
\hline & & Back Ground Color & 1 \\
\hline & & Fore Ground color & 1 \\
\hline & & Tables & 1 \\
\hline & & Images & 1 \\
\hline & & Videos & 1 \\
\hline & & Audios & 1 \\
\hline
\end{tabular}


B. Vishnu Priya et al., International Journal of Emerging Trends in Engineering Research, 7(10), October 2019, 360 - 375

Table 5: Experimental results for a sample Web site

\begin{tabular}{|c|c|c|c|c|c|c|c|c|c|c|}
\hline $\begin{array}{c}\text { Serial } \\
\text { number }\end{array}$ & Resource files & $\begin{array}{c}\text { Type of } \\
\text { object }\end{array}$ & $\begin{array}{l}\text { Numbe } \\
\text { r of } \\
\text { Objects }\end{array}$ & $\begin{array}{l}\text { Object } \\
\text { Number }\end{array}$ & Characteristic & Computed Value & Standard value & Variation & $\begin{array}{c}\text { Variation } \\
\%\end{array}$ & $\begin{array}{l}\text { Quality } \\
\text { Value }\end{array}$ \\
\hline \multirow{12}{*}{1} & \multirow{12}{*}{ Registrations.html } & \multirow{5}{*}{ font } & \multirow{5}{*}{1} & \multirow{5}{*}{1} & Type & Time New Roman & $\begin{array}{ll}\text { Time } & \text { New } \\
\text { Roman } & \end{array}$ & 0 & \multirow{5}{*}{40} & \multirow{5}{*}{0.6} \\
\hline & & & & & Style & Italic & Regular & -1 & & \\
\hline & & & & & Size & 11 & 11 & 0 & & \\
\hline & & & & & Color & 40 & 40 & 0 & & \\
\hline & & & & & Case & Low Case & Sentence & -1 & & \\
\hline & & \multirow{4}{*}{ Text } & \multirow{4}{*}{1} & \multirow{4}{*}{1} & $\begin{array}{l}\text { Paragraph } \\
\text { Margin }\end{array}$ & 6 & 6 & 0 & \multirow{4}{*}{0} & \multirow{4}{*}{1.0} \\
\hline & & & & & Front space & 6 & 6 & 0 & & \\
\hline & & & & & Back Space & 6 & 6 & 0 & & \\
\hline & & & & & Style & Regular & Regular & 0 & & \\
\hline & & \multirow{3}{*}{$\begin{array}{c}\text { Back } \\
\text { Ground } \\
\text { Color }\end{array}$} & \multirow{3}{*}{1} & \multirow{3}{*}{1} & Red & 65 & 65 & 0 & \multirow{3}{*}{0} & \multirow{3}{*}{1.0} \\
\hline & & & & & YELLOW & 65 & 65 & 0 & & \\
\hline & & & & & Blue & 65 & 65 & 0 & & \\
\hline & & \multirow{3}{*}{$\begin{array}{l}\text { Fore } \\
\text { Ground } \\
\text { color }\end{array}$} & \multirow{3}{*}{1} & \multirow{3}{*}{1} & Red & 65 & 65 & 0 & \multirow{3}{*}{0} & \multirow{3}{*}{1.0} \\
\hline & & & & & YELLOW & 65 & 65 & 0 & & \\
\hline & & & & & Blue & 65 & 65 & 0 & & \\
\hline
\end{tabular}


B. Vishnu Priya et al., International Journal of Emerging Trends in Engineering Research, 7(10), October 2019, 360 - 375

\begin{tabular}{|c|c|c|c|c|c|c|c|c|c|c|}
\hline $\begin{array}{c}\text { Serial } \\
\text { number }\end{array}$ & Resource files & $\begin{array}{c}\text { Type of } \\
\text { object }\end{array}$ & $\begin{array}{l}\text { Number } \\
\text { of } \\
\text { Objects }\end{array}$ & $\begin{array}{l}\text { Object } \\
\text { Number }\end{array}$ & Characteristic & Computed Value & Standard value & Variation & $\begin{array}{c}\text { Variation } \\
\%\end{array}$ & $\begin{array}{l}\text { Quality } \\
\text { Value }\end{array}$ \\
\hline \multirow{14}{*}{1} & \multirow{14}{*}{ Registrations.htm } & \multirow{14}{*}{ Tables } & \multirow{14}{*}{1} & \multirow{14}{*}{1} & \multirow{3}{*}{$\begin{array}{c}\text { Column } \\
\text { Heading Color }\end{array}$} & 50 & 50 & \multirow{3}{*}{0} & \multirow{3}{*}{0} & \multirow[t]{3}{*}{1.0} \\
\hline & & & & & & 50 & 50 & & & \\
\hline & & & & & & 50 & 50 & & & \\
\hline & & & & & Font Type & Regular & Regular & 0 & 0 & 1.0 \\
\hline & & & & & Font Style & Bold & Bold & 0 & 0 & 1.0 \\
\hline & & & & & Font Size & 11 & 11 & 0 & 0 & 1.0 \\
\hline & & & & & \multirow{4}{*}{ Font Color } & Red & 60 & \multirow{4}{*}{0} & \multirow{4}{*}{0} & \multirow{4}{*}{1.0} \\
\hline & & & & & & Yellow & 60 & & & \\
\hline & & & & & & Blue & 60 & & & \\
\hline & & & & & & Case & Regular & & & \\
\hline & & & & & \multirow[t]{4}{*}{ Text } & Paragraph Margin & 6 & \multirow{4}{*}{0} & \multirow{4}{*}{0} & \multirow{4}{*}{1.0} \\
\hline & & & & & & Front space & 6 & & & \\
\hline & & & & & & Back Space & 6 & & & \\
\hline & & & & & & Style & Regular & & & \\
\hline \multirow{8}{*}{1} & \multirow{8}{*}{ Registrations.html } & \multirow{3}{*}{ Images } & \multirow[t]{3}{*}{1} & \multirow[t]{3}{*}{1} & Width in Pixel & 800 & 1100 & -1 & \multirow{3}{*}{66} & \multirow{3}{*}{0.33} \\
\hline & & & & & $\begin{array}{l}\text { Height in } \\
\text { Pixel }\end{array}$ & 800 & 1100 & -1 & & \\
\hline & & & & & Colors & 40 & 40 & 0 & & \\
\hline & & \multirow{4}{*}{ Videos } & \multirow{4}{*}{1} & \multirow{4}{*}{1} & Width in Pixel & 1100 & 1100 & 0 & \multirow{4}{*}{0} & \multirow{4}{*}{1.0} \\
\hline & & & & & $\begin{array}{l}\text { Height in } \\
\text { Pixel }\end{array}$ & 1100 & 1100 & 0 & & \\
\hline & & & & & Colors & 45 & 45 & 0 & & \\
\hline & & & & & $\begin{array}{l}\text { Frames per } \\
\text { second }\end{array}$ & 10 & 10 & 0 & & \\
\hline & & Audios & 1 & 1 & Decibels & 1000 & 1000 & 0 & 0 & 1.0 \\
\hline
\end{tabular}

